\title{
Determinants of carbon load in airway macrophages in pregnant women ${ }^{\text {th }}$
}

\author{
Mohammad Miri ${ }^{\text {a }}$, Hossein Rezaei ${ }^{\mathrm{b}}$, Seyed Mojtaba Momtaz ${ }^{\mathrm{c}}$, Moslem Lari Najafi ${ }^{\mathrm{d}}$, \\ Abolfazl Adli ${ }^{\mathrm{e}}$, Nasim sadat Pajohanfar ${ }^{\mathrm{e}}$, Mina Abroudi ${ }^{\mathrm{e}}$, Malihe Sadat Bazghandi ${ }^{\mathrm{e}}$, \\ Zahra Razavi ${ }^{\mathrm{e}}$, Lucia Alonso ${ }^{\mathrm{f}, \mathrm{g}, \mathrm{h}}$, Cathryn Tonne ${ }^{\mathrm{f}, \mathrm{g}, \mathrm{h}}$, Xavier Basagaña ${ }^{\mathrm{f}, \mathrm{g}, \mathrm{h}}$, \\ Mark J. Nieuwenhuijsen ${ }^{f, g, h}$, Jordi Sunyer ${ }^{f, g, h}$, Tim S. Nawrot ${ }^{i, j}$, Payam Dadvand ${ }^{\mathrm{f}, \mathrm{g}, \mathrm{h}, *}$ \\ ${ }^{\text {a }}$ Non-Communicable Diseases Research Center, Department of Environmental Health, School of Health, Sabzevar University of Medical Sciences, Sabzevar, Iran \\ ${ }^{\mathrm{b}}$ Student Research Committee, Department of Environmental Health, School of Health, Sabzevar University of Medical Sciences, Sabzevar, Iran \\ ${ }^{\mathrm{c}}$ Department of Environmental Health Engineering, Zarand School of Nursing, Kerman University of Medical Sciences, Kerman, Iran \\ d Pharmaceutical Sciences and Cosmetic Products Research Center, Kerman University of Medical Sciences, Kerman, Iran \\ e Cellular and Molecular Research Center, Sabzevar University of Medical Sciences, Sabzevar, Iran \\ ${ }^{\mathrm{f}}$ ISGlobal, Barcelona, Spain \\ ${ }^{g}$ Universitat Pompeu Fabra (UPF), Barcelona, Spain \\ ${ }^{\mathrm{h}}$ CIBER Epidemiología y Salud Pública (CIBERESP), Spain \\ ${ }^{\mathrm{i}}$ Centre for Environmental Sciences, Hasselt University, Hasselt, Belgium \\ ${ }^{\mathrm{j}}$ Department of Public Health \& Primary Care, Leuven University, Leuven, Belgium
}

\section{A R T I C L E I N F O}

\section{Keywords:}

Air pollution

Pregnancy

Biomarker

Phagocytosis

Lung

\begin{abstract}
A B S T R A C T
The airway macrophages carbon loading (AMCL) has been suggested to be a biomarker of the long-term exposure to air pollution; however, to date no study has characterized AMCL for the pregnancy period. Therefore, this study aimed to assess the determinants of AMCL during pregnancy in Iran, a middle-income country. This study was based on a sample of 234 pregnant women with term and normal vaginal delivery who were residing in Sabzevar, Iran (2019). We characterized 35 potential determinants of personal exposure to air pollution for each participant, including six personal, nine indoor, and 20 home-outdoor factors. We applied Deletion/Substitution/ Addition algorithm to identify the most relevant determinants that could predict AMCL levels. The median (IQR) of AMCL level was $0.12(0.30) \mu \mathrm{m}^{2}$ with a successful sputum induction in $82.9 \%$ (194) of participants. Ambient residential $\mathrm{PM}_{2.5}$ levels were positively associated with higher AMCL levels. On the other hand, increased residential distance to the traffic lights, squares and ring-roads, the duration of opening window per day, and opening window during cooking were inversely associated with AMCL levels. Our findings provide novel insights on the different personal, indoor, and outdoor determinants of personal exposure to air pollution during pregnancy in a middle-income country.
\end{abstract}

\section{Introduction}

Air pollution is a major environmental hazard worldwide. More than $98 \%$ of the global population lives in areas that do not meet World Health Organization (WHO) air quality guidelines and, at the same time, there is a notable difference between high-, middle-, and low-income countries in this regard (WHO, 2021). While, in high-income countries, about half of the cities with a population of more than 100000 inhabitants do not meet WHO air quality recommendations, this proportion reaches $97 \%$ in low- and middle-income countries (LMICs) cities. This difference in air pollution levels is accompanied by a considerably greater health burden of air pollution in LMICs. More than $90 \%$ of the annual 4.2 million premature deaths that could be attributed to air pollution worldwide, occur in LMICs (WHO, 2021). At the same time, whilst studies on determinants of the personal exposure to air pollution could provide an evidence base necessary to fine-tune targeted interventions to tackle the burden of air pollution, a vast majority of these studies have been conducted in high-income countries whose finding are not necessarily generalizable to LMICs, for which such evidence is still very scarce (Milà et al., 2018; Curto et al., 2019; Sanchez

\footnotetext{
This paper has been recommended for acceptance by Wen Chen.

* Corresponding author. Barcelona Institute for Global Health (ISGlobal), Doctor Aiguader 88, Barcelona, 08005, Spain.

E-mail address: Payam.dadvand@isglobal.org (P. Dadvand).
} 


\section{et al., 2020; Shupler et al., 2020).}

Pregnant women and developing foetus are particularly vulnerable to air pollution exposure. This exposure has been associated with a higher risk of pregnancy complications (e.g., preeclampsia, gestational diabetes) as well as adverse birth outcomes (e.g., low birth weight and preterm birth) (Melody et al., 2019; Bai et al., 2020). In this context, identifying the determinants of personal exposure to air pollution during pregnancy is of importance for both researchers and policymakers. Given the logistical and perhaps ethical constraints of conducting long-term personal monitoring of exposure to air pollution in pregnant women using personal samplers (Valero et al., 2009; Schembari et al., 2013), studies for identifying the determinants of personal air pollution exposure during pregnancy could benefit from novel biomarkers of this exposure (e.g. (Øvrevik, 2019; Li et al., 2020; Zhao et al., 2020), notably carbon load in airway macrophages (Bai et al., 2015a). Airway macrophages phagocyte the inhaled particles that are presented on the epithelial surfaces in the lumen of the bronchi and alveoli (Lundborg et al., 2006). Therefore, the carbon core of particles emitted from different sources, e.g., traffic, smoking and indoor sources, can be visualized inside the airway macrophages using light microscopy (Lundborg et al., 2006; Bai et al., 2015a). As such, airway macrophages carbon load (AMCL) has been used as a marker of personal exposure to ambient and indoor air pollution (Kulkarni et al., 2005; Kulkarni et al., 2006; McCreanor et al., 2007; Fullerton et al., 2009; Bai et al., 2015b; Bai et al., 2018a; Bai et al., 2018b; Momtaz et al., 2019). In this context, the AMCL has been suggested as a marker of long-term exposure to air pollution for up to six months (Bai et al., 2015a); thus, the AMCL based on the samples taken at the end of pregnancy could surrogate exposure to air pollution during the most of pregnancy period. However, to date, no study has applied AMCL in pregnant women. Accordingly, we aimed to investigate the level and determinants of AMCL levels in a sample of pregnant women in Iran, a middle-income country.

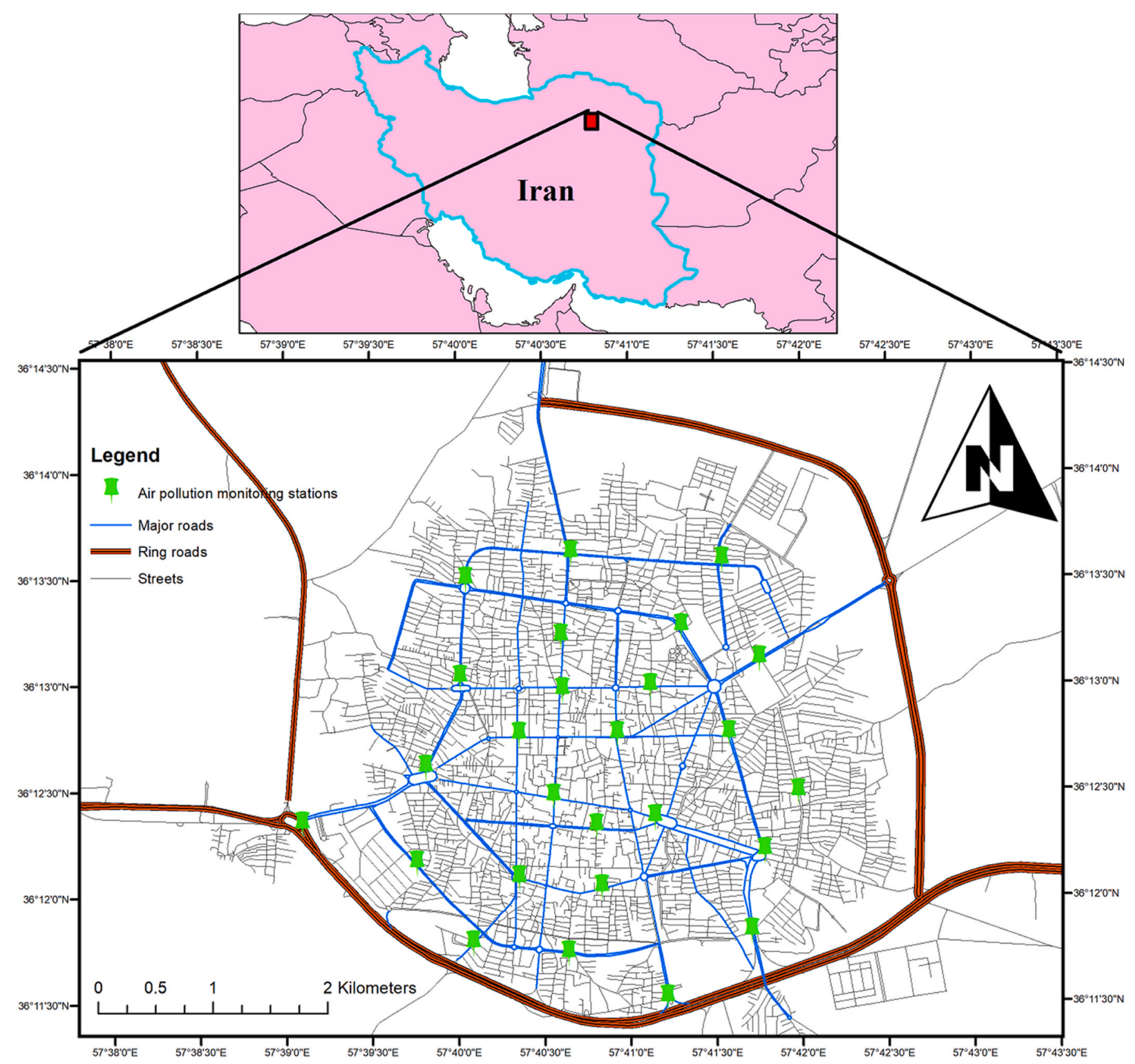

Fig. 1. Location of study area, monitoring stations of air pollution, roads and other traffic indicators. 


\section{Material and methods}

\subsection{Study area and population}

This study was conducted in Sabzevar, a town with a $25 \mathrm{~km}^{2}$ area and a population of about 240000 inhabitants in the northeast of Iran (Fig. 1). Being located at the verge of the central desert in the Iran plateau, Sabzevar has an arid climate with an annual average precipitation and relative humidity of $170 \mathrm{~mm}$ and $43 \%$, respectively (Office, 2020). The annual mean, average minimum and average maximum temperature in Sabzevar is respectively $18,-2$ and $45^{\circ} \mathrm{C}$. One of the main highways in Iran passes through Sabzevar, contributing to the traffic-related air pollution in the city.

This study was based on a pregnancy cohort of 234 pregnant women enrolled at their delivery time during summer months (June to August) of 2018 in the Shahidan Mobini Hospital, the only maternity hospital of the Sabzevar. We included pregnant women with (i) normal vaginal delivery, (ii) gestational age of 37-43 weeks at delivery (i.e. term delivery), (iii) no chronic diseases such as diabetes or hypertension or pregnancy complications such as preeclampsia, (iv) who lived in Sabzevar during the entire pregnancy, (v) did not work outside the home, (vi) were not active smoker, and (vii) did not change their home during pregnancy. First, inclusion/exclusion criteria, aims and steps of the study were fully described for mothers who attended the hospital for delivery (about 1200 mothers) and 234 eligible mothers accepted our invitation to participate in the study. We carried out face-to-face interviews to obtain questionnaire data on socioeconomic and demographic characteristics as well as lifestyle habits. The Clinical Research Ethical Committee of Sabzevar University of Medical Sciences approved our study (IR.MEDSAB.REC.1395.82) and all participants signed an informed consent form before their enrolment into the cohort.

\subsection{Sputum induction and AMCL measurements}

The sputum samples were optioned one day after delivery at the hospital. The sputum induction was based on the method described by Scheicher et al. (2003), with slight modifications. An ultrasonic nebulizer device (1.7 MHz, NE-U17, Omron Healthcare Co., Ltd., Kyoto, Japan) was used to assist the inhalation of a $4.5 \%$ saline solution three consecutive times, each lasting 5-min (cumulative duration of $15 \mathrm{~min}$ ) with a $5 \mathrm{~min}$ interval between each inhalation. We used salbutamol spray for participants who had coughs during inducing sputum. The sputum samples were collected in a sterilized plate and were transported to the laboratory within less than an hour near dry ice at four ${ }^{\circ} \mathrm{C}$. After the initial preparation, the slides of sputum samples were dried for $2 \mathrm{~h}$ at room temperature and then were stained by Diff Quick (Pavord et al., 1997). Light microscopy under oil immersion at $100 \times$ magnification was used to visualize the AMCL. Those participants whose sputum samples had less than 50 macrophages (Jacobs et al., 2010; Brugha et al., 2014; Bai et al., 2018b) were excluded from our analyses (40 participants). Finally, the images of 194 participants were analysed using ImageJ software (National Institutes of Health, USA) (ImageJ, 2020) to calculate the AMCL level in 50 randomly selected macrophages per participant, defined as the median area $\left(\mu \mathrm{m}^{2}\right)$ occupied by carbon (Jacobs et al., 2010; Brugha et al., 2014; Bai et al., 2018b). To provide more accuracy in our measurements, we checked some pictures with high level of spurious colors manually in the software. Moreover, the images with very high level of spurious colors/bacteria (where it was difficult to separate and detect carbon particles) were excluded from our analyses and replaced with new images from the slide. The image analyses for all participants were performed by two researchers independently (they were blinded to the exposure status of participants or any baseline information as well as their each other's results) and their results were compared by a third researcher (Brugha et al., 2012; Bai et al., 2015a). If the results of carbon loading measurements for each participant were exactly similar between the two raters (defined as the difference of lower than $\pm 0.001 \mu \mathrm{m}^{2}$ between the median AMCL levels of 50 images reported by the two raters), we reported this value as the final AMCL level for that sample. For the samples for which the difference in the reported median levels of carbon loading was more than $\pm 0.001 \mu \mathrm{m}^{2}$, we reanalysed it again by three researchers at the same computer through an open discussion about each image. Finally, an agreement was reached between the three researchers on the level of AMCL in the discussed samples.

\subsection{Determinants of exposure}

We obtained data on six, nine, and 20 personal, home-indoor, and home-outdoor factors, respectively, that we hypothesized could influence personal exposure to air pollution.

\subsubsection{Personal determinants}

The participant's information including age (year, continuous), prepregnancy body mass index $\left(\mathrm{kg} / \mathrm{m}^{2}\right.$, continuous), pre-pregnancy weight (kg, continuous), height (meter, continuous), education level (high school and/or lower, university degree) and family income $(<15$ million, $\geq 15$ million Rials) were collected using a questionnaire through a face-to-face interview.

\subsubsection{Indoor determinates}

Indoor determinants encompassed second-hand tobacco smoke at home during pregnancy (yes/no), duration of second-hand tobacco smoke at home during pregnancy ( $\mathrm{min} /$ day), second-hand tobacco smoke in other places than home (e.g. public places, cafes, friend's homes, etc.) (yes/no), type of kitchen (open-plan kitchen vs. walled kitchen), use of kitchen hood during cooking (yes/no), opening window during cooking (yes/no), duration of opening window per day (min/ day), the average daily cooking time during pregnancy (min/day), and type of home (Single-family house/apartment). It should be noted that in Sabzevar, like most cities in Iran, residents have access to natural gas through the national gas pipeline and as such, all participants of the study used natural gas for cooking and heating at their homes; therefore, we did not use this information in our analyses. The data on these indoor determinates were collected through face-to-face interview.

\subsubsection{Home-outdoor determinants}

The annual mean concentration of $\mathrm{PM}\left(\mathrm{PM}_{1}, \mathrm{PM}_{2.5}, \mathrm{PM}_{10}\right)$ at residential address of participants was estimated based on land use regression (LUR) models, developed for Sabzevar. These LUR models were generated based on data obtained from 26 air pollution monitoring sites in Sabzevar (Fig. 1). These models could predict between $68 \%$ and $75 \%$ of the variation in the annual mean of these PMs. The details of PM measurement campaigns and LUR model development and performance were fully described elsewhere (Miri et al., 2019).

The data on total street length in 100, 300 and $500 \mathrm{~m}$ buffers around the residential address of participants and the residential distance to the nearest ring roads and major roads were calculated based on the street map of Sabzevar, provided by the Municipality of Sabzevar (2019). The data on the residential distance to the bus terminal, transportation land use (parking, cargo terminals, etc.), industrial land use, residentialindustry land use, squares, mosque/religious places, and government offices were calculated based on the aforementioned land use map of Sabzevar. Moreover, distance from home to the nearest public parking, bus station, heavy traffic-light (based on the classification of Open Street Map (OSM)), gas stations and ATM banks were calculated based on data of OSM of Sabzevar.

\subsection{Statistical analysis}

We used different correlation coefficients (Spearman's correlation for two continuous variables, polychoric correlation for two categorical variables, or polyserial correlation for one categorical and one 
continuous variable) to generate the correlation matrix of the determinants of AMCL.

The Deletion/Substitution/Addition (DSA) algorithm was applied to identify the most relevant determinants that could predict AMCL levels. Barrera-Gomez et al. and Agier et al. have suggested the DSA algorithm as a method with better performance in selecting variables compared other methods on the basis of its sensitivity, low false detection proportion, and ability to correct for correlated exposures (Agier et al., 2016; Barrera-Gómez et al., 2017). In the DSA algorithm, an empty model is started and the final model is created based on iteratively applying the following steps: i) removing a variable from the model (deletion) if this improves model fit, ii) replacing a variable in the model by another one not in the model (substitution) if this improves model fit or iii) adding a variable in the model (addition) if this improves model fit. An improvement of model fit is considered if the new model considered at a given step reduces the residual mean squared error (RMSE) calculated using 5-fold cross-validation. To stabilize the results for the random splitting of cross-validation, we ran DSA 50 times and we selected the variables that were selected by the algorithm at least once. For comparability between the estimates, all continuous determinants were divided by its interquartile range (IQR) before applying the DSA, so the reported associations were corresponding to one IQR increase in each exposure value. All analyses were performed with the $\mathrm{R}$ statistical software (version 3.6.2), using the DSA package.

\section{Results}

\subsection{Determinants}

Descriptive statistics of personal, indoor and home-outdoor determinants, as well as AMCL level in pregnant women are presented in Table 1. The median (IQR) age and pre-pregnancy BMI of the participants were $27.5(8.0)$ years and $23.9(5.7) \mathrm{kg} / \mathrm{m}^{2}$, respectively. Most of the mothers had primary or high school education levels $(71.7 \%)$. Moreover, 42 (21.7\%) and 77 (39.7\%) of mothers had second-hand tobacco smoke exposure at respectively home and other places than home during pregnancy. About $47 \%$ of mothers used kitchen hood during cooking and $60 \%$ of mothers used natural ventilation (opening the window) during cooking. The median (IQR) of estimated annual ambient levels of $\mathrm{PM}_{10}, \mathrm{PM}_{2.5}, \mathrm{PM}_{1}$ at participants' homes were 47.7 (12.2), 43.8 (10.3), and $38.9(9.4) \mu \mathrm{g} / \mathrm{m}^{3}$, respectively.

The success rate of sputum acquisition for measuring AMCL in participants was $82.9 \%$ (194 participants). Fig. 2 shows the airway macrophages of sputum samples with a high carbon load level (Fig. 2 -A) and without any carbon load in the airway macrophages (Fig. $2-\mathrm{B})$. The median (IQR) of AMCL in pregnant women was $0.12(0.30) \mu \mathrm{m}^{2}$.

\subsection{Correlation between determinants}

The correlation between personal, indoor and outdoor determinates of personal exposure to air pollution during pregnancy are presented in Fig. 3. There was a positive but weak correlation between using hood and the amount time of cooking during pregnancy $(r=0.11)$. We also observed a negative correlation between second-hand tobacco smoke as well as duration of exposure to tobacco smoke at home during pregnancy and maternal education. Moreover, there was a weak correlation between personal and indoor determinants with estimated PMs as well as traffic indicators. There was a negative correlation between PMs and traffic indicators, e.g., distance to major roads, ring roads, the bus terminal and heavy-traffic lights. Moreover, a strong correlation was observed between the estimated $\mathrm{PM}_{1}$ and $\mathrm{PM}_{2.5}$, while $\mathrm{PM}_{10}$ was moderately correlated with $\mathrm{PM}_{2.5}$ and $\mathrm{PM}_{1}$.

\subsection{Main analyses}

The estimated associations of determinates of personal exposure to
Table 1

Descriptive statistics of personal, indoor and outdoor determinants of exposure to air pollution during pregnancy.

\begin{tabular}{|c|c|}
\hline & Description $^{\mathrm{a}}$ \\
\hline \multicolumn{2}{|l|}{ Personal determinants } \\
\hline Maternal age (yr) & $27.5(8.0)$ \\
\hline Mothers weight $(\mathrm{kg})$ & $61.5(15.0)$ \\
\hline Mothers hight (m) & $1.6(0.1)$ \\
\hline Pre-pregnancy BMI (kg/m2) & $23.9(5.7)$ \\
\hline \multicolumn{2}{|l|}{ Matenal education, } \\
\hline Elementry and high-school & $139(71.7)$ \\
\hline University & $55(28.3)$ \\
\hline \multicolumn{2}{|l|}{ Income } \\
\hline$<1.5$ milion Rials & $139(71.7)$ \\
\hline$\geq 1.5$ milion Rials & $55(28.3)$ \\
\hline \multicolumn{2}{|l|}{ Indoor determinants } \\
\hline The average daily cooking time during pregnancy $(\mathrm{min} /$ day) & $120.0(120.0)$ \\
\hline $\begin{array}{l}\text { Duration of second-hand tobacco smoke at home during } \\
\text { pregnancy }\end{array}$ & $30.0(78.0)$ \\
\hline $\begin{array}{l}\text { Duration of opening window per day during pregnancy (min/ } \\
\text { day) }\end{array}$ & $180.0(60.0)$ \\
\hline $\begin{array}{l}\text { Second-hand tobacco smoke exposure at home during pregnancy } \\
\text { (Yes) }\end{array}$ & $42(21.7)$ \\
\hline Using kitchen hood during cooking (Yes) & $102(52.6)$ \\
\hline $\begin{array}{l}\text { Second-hand tobacco smoke exposure in other places than home } \\
\text { (Yes) }\end{array}$ & 77 (39.7) \\
\hline \multicolumn{2}{|l|}{ Type of home } \\
\hline Single-family house (vila) & $103(53.1)$ \\
\hline Apartement & $91(46.9)$ \\
\hline \multicolumn{2}{|l|}{ Type of kitchen } \\
\hline Open-plan kitchen & $28(14.4)$ \\
\hline Walled kitchen & $166(85.6)$ \\
\hline \multicolumn{2}{|l|}{ Opening window during cooking } \\
\hline Rarely/No & $117(60.3)$ \\
\hline Some time/Always & $77(39.7)$ \\
\hline \multicolumn{2}{|l|}{ Outdoor determinants } \\
\hline $\mathrm{PM}_{10}\left(\mu \mathrm{g} / \mathrm{m}^{3}\right)$ & $47.7(12.2)$ \\
\hline $\mathrm{PM}_{2.5}\left(\mu \mathrm{g} / \mathrm{m}^{3}\right)$ & $43.8(10.3)$ \\
\hline $\mathrm{PM}_{1}\left(\mu \mathrm{g} / \mathrm{m}^{3}\right)$ & $38.9(9.4)$ \\
\hline \multicolumn{2}{|l|}{ Total street length around residential address (m) } \\
\hline $100 \mathrm{~m}$ buffer & $886.4(206.1)$ \\
\hline $300 \mathrm{~m}$ buffer & $7417.6(2200.2)$ \\
\hline \multirow[t]{2}{*}{$500 \mathrm{~m}$ buffer } & 19834.2 \\
\hline & (6971.4) \\
\hline Distance to major roads $(\mathrm{m})$ & $232.1(298.7)$ \\
\hline Distance to the bus terminal (m) & $2983.6(1916.7)$ \\
\hline Distance to transportation land use (m) & $168.4(212.1)$ \\
\hline Distance to industrial land use (m) & $197.4(268.4)$ \\
\hline Distance to residential-industry land use (m) & $122.5(212.7)$ \\
\hline Distance to ATM banks (m) & $577.3(608.7)$ \\
\hline Distance to gas stations (m) & $996.1(413.5)$ \\
\hline Distance to heavy trrafic_lights (m) & $471.5(561.2)$ \\
\hline Distance to squares (m) & $289.4(256.0)$ \\
\hline Distance to the bus station (m) & $817.5(788.8)$ \\
\hline Distance to musque/religious places (m) & $599.1(629.8)$ \\
\hline Distance to ring roads $(\mathrm{m})$ & $1022.7(721.8)$ \\
\hline Distance to public parking (m) & $814.7(559.1)$ \\
\hline Distance to government offices (m) & $200.3(238.7)$ \\
\hline Airway macrophages carbon loading $\left(\mu \mathrm{m}^{2}\right)$ & $0.12(0.30)$ \\
\hline
\end{tabular}

${ }^{a}$ Continuous variables are presented as median (interquartile range) and categorical variables as count (\%).

${ }^{\mathrm{b}}$ Reported as mean (standard deviation).

air pollution based on AMCL are presented in Table 2. The results of the DSA algorithm of 20 outdoor, nine indoor and six personal determinants indicated that home-outdoor levels of $\mathrm{PM}_{2.5}$, residential distance to heavy-traffic lights, squares and ring-roads, existence and duration of the daily opening window at home, duration of the second-hand tobacco smoke exposure at home, type of kitchen, and participant's age were the most relevant indicators in association with AMCL.

An IQR increase in residential ambient $\mathrm{PM}_{2.5}$ concentration was related with an increase of $0.351 \mu \mathrm{m}^{2}$ (95\% confidence interval (CI): $0.186,0.517$, P-value $<0.01$ ) in AMCL. Moreover, longer exposure to the second-hand tobacco smoke at home during pregnancy was related with higher AMCL levels. An IQR increase in the residential distance to 

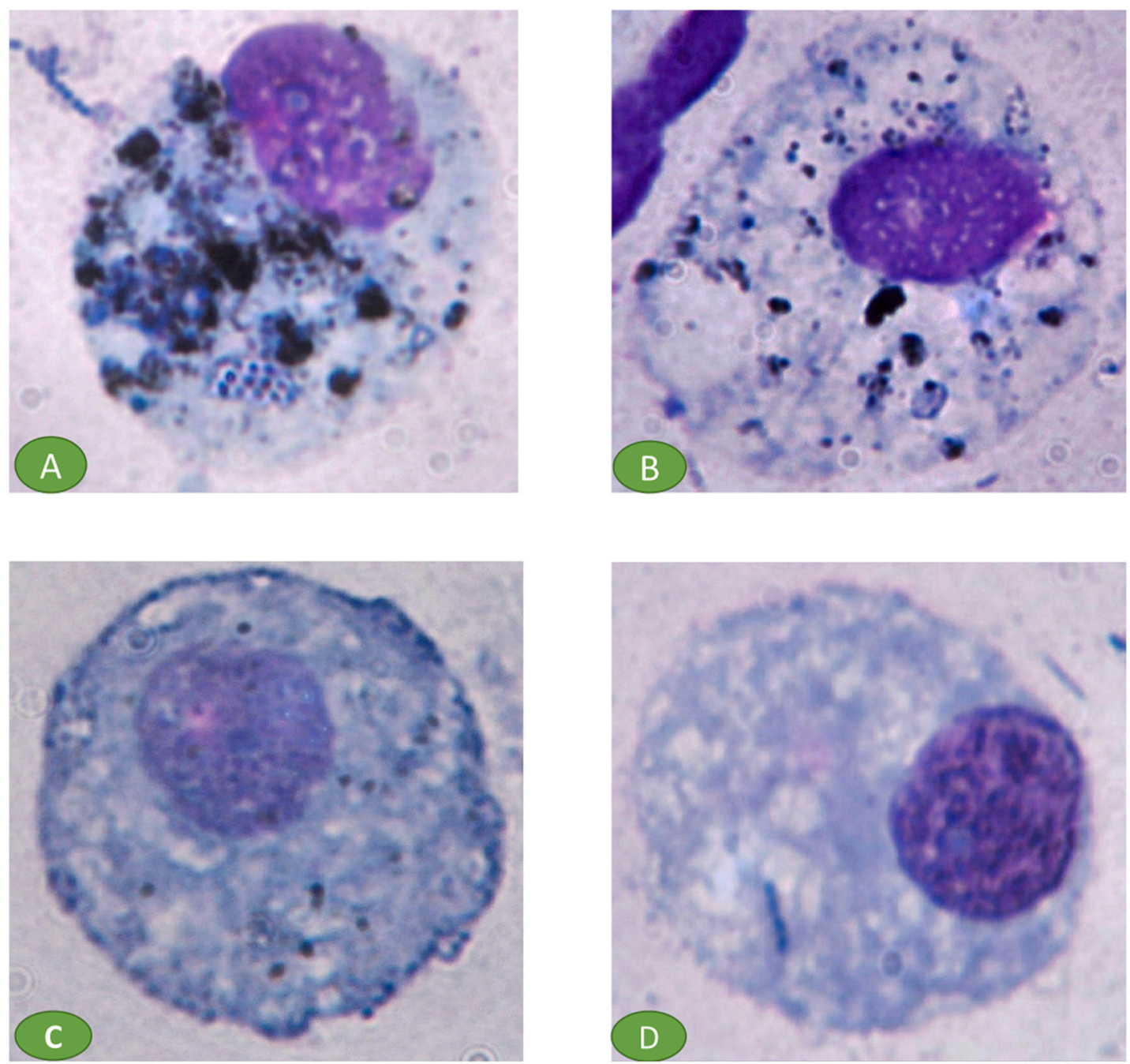

Fig. 2. Fig. 2: Airway macrophages of sputum samples with a high carbon load level (Fig. $2-$ A and $2-$ B), with low carbon load level (Fig. $2-$ C) and without any carbon load (Fig. 2 -D).

heavy-traffic lights, squares, and ring-roads was related with a decrease of respectively $-0.486 \mu \mathrm{m}^{2}$ (95\%CI: $0.833,-0.139$, P-value $<0.01$ ), $-0.266 \mu \mathrm{m}^{2}$ (95\%CI: 0.505, -0.026 , P-value $=0.03$ ) and $-0.511 \mu \mathrm{m}^{2}$ $(-0.835,-0.187$, P-value $<0.01)$ in AMCL levels. Furthermore, longer duration of daily opening window of home ( $\beta=-0.223$, $95 \%$ CI: 0.392 , -0.053 , P-value $=0.03)$, opening window during cooking $(\beta=-0.576$, 95\% CI: 0.971, -0.181 , P-value $<0.01)$, and older age $(\beta=-0.028,95 \%$ CI: $0.063,0.007, \mathrm{P}$-value $=0.11$ ) were inversely associated with AMCL levels. Additionally, maternal age, kitchen type, and the duration of exposure to the second-hand tobacco smoke at home during pregnancy stayed in the final model; however, their association with AMCL did not attain statistical significance (Table 2).

\section{Discussion}

To the best of our knowledge, this study is the first to characterize AMCL during pregnancy. Furthermore, this is the first study to explore the personal, indoor and outdoor determinates of personal exposure to air pollution in pregnant women in an LMIC. Moreover, this is one of the largest reported studies on characterization of AMCL levels. Furthermore, measuring the AMCL was performed by two independent investigators and checked by third investigator to reduce the AMCL measurement bias. We observed that the estimated ambient $\mathrm{PM}_{2.5}$ levels at residential address was positively associated with AMCL. On the other hand, residential distance to heavy-traffic lights, squares and ring-roads, the duration of opening window per day, and opening window during cooking were inversely associated with AMCL levels.

\subsection{AMCL level and sputum induction}

The median (IQR) of AMCL level in our study was $0.12(0.30) \mu \mathrm{m}^{2}$, with a sputum acquisition success rate of $82.9 \%$, which are compatible with those previous studies. A study by Bai et al. (2018), in 43 adult subjects reported a median (IQR) AMCL level of $0.346(0.314) \mu \mathrm{m}^{2}$ with a success rate of $76.0 \%$ in sputum induction (Bai et al., 2018a). Another study by Kulkarni et al. (2006), reported a median (range) AMCL of 0.41 $(0.03-1.14)$ and $0.00(0.00-0.12) \mu \mathrm{m}^{2}$ for 64 healthy children and nine children with asthma with a successful ratio of sputum induction of $56 \%$ and $100 \%$, respectively (Kulkarni et al., 2006). A study by Jacobs et al. (2010), on 137 adults with diabetes reported a median (range) of 0.19 (0.09-0.34) $\mu \mathrm{m}^{2}$ for AMCL levels with a success rate of $87 \%$ (Jacobs et al., 2010). Moreover, a review study by Bai et al. (2015) on AMCL reported a success ratio between 56 and $100 \%$ based on six different studies (Bai et al., 2015a). Obtaining the sufficient number of macrophages in the samples could be influenced by personal factors (e.g., the squamous epithelial contamination), subject-specific physiological features, and technical factors such as time course of inhalation (cumulative duration of 15-21 $\mathrm{min}$ ), pre-treatment with salbutamol, incremental changes in saline concentration, and the use of an ultrasonic nebulizer (Bai et al., 2015a). 


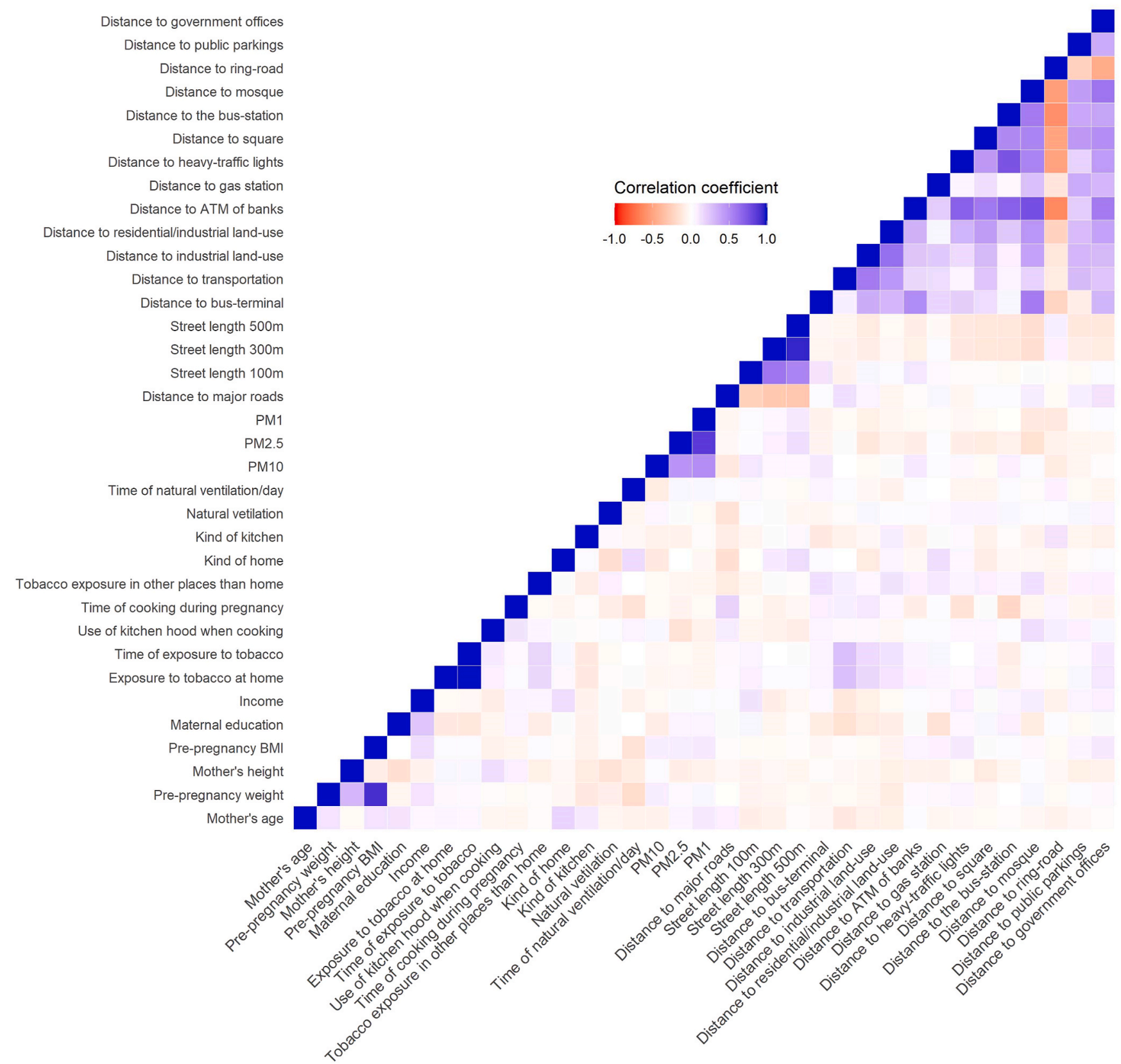

Fig. 3. Corrlation of personal, indoor and outdoor determinants of expsoure to air pollution.

\subsection{Determinants of AMCL}

We are not aware of any study on the determinates of AMCL levels in pregnant women; therefore, we are not able to compare our observations with those of previous research. However, the available evidence in other populations suggested that traffic-related air pollution, indoor air pollution (e.g., exposure to tobacco smoke and biomass burning) and personal characteristics could be associated with AMCL level (Bai et al., 2015a; Belli et al., 2016; Whitehouse et al., 2018; Momtaz et al., 2019; Rezaei Hachesu et al., 2019). Regarding personal determinants, we observed that the participant's age was inversely, although statistically non-significant, associated with AMCL levels. Majority of the previous studies did not find any relationship between personal characteristics such as age, sex, weight, height and BMI with AMCL level (Jacobs et al., 2010; Bai et al., 2015a). Similarly, in our study, weight, height, and BMI did not appear to influence the AMCL levels. However, experimental research showed that particle deposition in the respiratory tract could be affected by different mechanisms and physical characteristics of participants (e.g., BMI and age) could have various effects on it (Bennett et al., 1996; Bennett and Zeman, 2004; Bai et al., 2015a). Furthermore, human and animal model studies suggested that with aging, alveolar macrophages phagocytosis and their number could reduce significantly (Linehan and Fitzgerald, 2015; Wong et al., 2017), which, in turn could result in reducing AMCL levels.

Regarding indoor determinants, we observed an inverse association between having and the duration of opening window per day with AMCL levels. Moreover, open-plan kitchen and the duration of exposure to the second-hand tobacco smoke at home during pregnancy stayed in the final model and showed positive, though statistically non-significant, association with AMCL. Lack or less time of opening windows during cooking and/or the amount time of opening window per day could lead to the accumulation of indoor air pollutants and higher exposure levels. Previous studies suggested that natural ventilation (e.g., opening window) could significantly decrease indoor air pollution (Chang et al., 
Table 2

The determinates of airways macrophage carbon load based on Deletion/Substitution/Addition (DSA) algorithm.

\begin{tabular}{|c|c|c|}
\hline & Estimate (95\% CI) & $\begin{array}{l}P \\
\text { value }\end{array}$ \\
\hline Ambient residential $\mathrm{PM}_{2.5}{ }^{\mathrm{a}}$ & $0.351(0.186,0.517)$ & $<0.01$ \\
\hline Distance to heavy traffic-lights ${ }^{a}$ & $\begin{array}{l}-0.486(-0.833 \\
-0.139)\end{array}$ & $<0.01$ \\
\hline Distance to squares ${ }^{\text {a }}$ & $\begin{array}{l}-0.266(-0.505 \\
-0.026)\end{array}$ & 0.03 \\
\hline Distance to ring roads ${ }^{a}$ & $\begin{array}{l}-0.511(-0.835 \\
-0.187)\end{array}$ & $<0.01$ \\
\hline $\begin{array}{l}\text { Duration of opening window per day during } \\
\text { pregnancy }^{\text {a }}\end{array}$ & $\begin{array}{l}-0.223(-0.392 \\
-0.053)\end{array}$ & 0.01 \\
\hline $\begin{array}{l}\text { Duration of second-hand tobacco smoke at home } \\
\text { during pregnancy }\end{array}$ & $0.002(0.000,0.004)$ & 0.12 \\
\hline Walled kitchen & $\begin{array}{l}-0.412(-0.975 \\
0.151)\end{array}$ & 0.15 \\
\hline Opening window during cooking & $\begin{array}{l}-0.576(-0.971 \\
-0.181)\end{array}$ & $<0.01$ \\
\hline Maternal age $^{\mathrm{a}}$ & $\begin{array}{l}-0.028(-0.063 \\
0.007)\end{array}$ & 0.11 \\
\hline
\end{tabular}

${ }^{a}$ Effect estimates are reported as change in macrophages carbon loading $\left(\mu \mathrm{m}^{2}\right)$ with their $95 \%$ confidence interval $(95 \% \mathrm{CI})$ per one-interquartile range increase in each determinant and estimates are mutually adjusted.

2017; Spiru and Simona, 2017). A study by Schembari et al. (2013), for example, showed that natural ventilation of the home and the time spent cooking were statistically significant determinants of personal and indoor air pollution exposure in Spanish pregnant women (Schembari et al., 2013).

Previous studies suggested that tobacco smoke is a major source of indoor air pollution (Tarnoki et al., 2011; Masjedi et al., 2019). A study by Momtaz et al. on 160 healthy adults in Yazd, Iran, reported that the level of AMCL in passive smokers was significantly higher than those not exposed to tobacco smoke at home (Momtaz et al., 2019). Moreover, a study by White et al. (2019) on nine non-smoker adults reported that environmental tobacco smoke could be one of the major sources of AMCL level (White et al.). Our observed higher AMCL levels in participants living at homes with open-plan kitchen were in line with findings of the aforementioned study by Momtaz et al. in Iranian adults that reported that walled kitchen was significantly associated with a lower AMCL level (Momtaz et al., 2019).

In our study, the outdoor determinants, including $\mathrm{PM}_{2.5}$ levels (directly) and the residential distance to heavy-traffic lights, squares and ring-roads (inversely), were associated with AMCL levels. Fuel combustion is one of the main sources of $\mathrm{PM}_{2.5}$ in Iranian urban areas (Arhami et al., 2018; Soleimani et al., 2018); therefore, $\mathrm{PM}_{2.5}$ contains different carbonaceous species such as organic and black carbon (BC) (Hand et al., 2013; Kim et al., 2015; Pongpiachan et al., 2015; Arfaeinia et al., 2016; Al Hanai et al., 2019). Moreover, $\mathrm{PM}_{2.5}$-bounded carbonaceous species can easily be deposited deep into the lungs due to their small size. As such alveolar macrophages can directly encounter $\mathrm{PM}_{2.5}$ after inhaling polluted air and phagocyte them (Wei and Tang, 2018). A study by Belli et al. (2016) on 20 former smokers, showed that there was a significant direct relationship between short-term (5-7 days) and long-term (three to six months) exposure to indoor $\mathrm{PM}_{2.5}$ and AMCL; however, short and long-term exposure to outdoor $\mathrm{PM}_{2.5}$ were not statistically significantly associated with AMCL levels (Belli et al., 2016). Another study by Whitehouse et al. (2018) on 57 non-pregnant Malawian women reported that there was not any association between short-term exposure ( $48 \mathrm{~h}$ personal monitoring) to $\mathrm{PM}_{2.5}$ and AMCL level (Whitehouse et al., 2018).

Regarding distance variables, we observed that longer distance to traffic sources (i.e., heavy traffic lights, square and ring roads) was associated with lower AMCL level, which could be due to lower exposure to ambient PM-bounded carbonaceous species. It has been reported that heavier vehicle categories (e.g., tracks) emit higher PM to the atmosphere (Timmers and Achten, 2016), and many of them cross the ring roads every day in Sabzevar. Moreover, in the heavy traffic lights and/or squares, the vehicles work in idle mode or move with heavy gear for a long time, leading to emitting BC (Rahman et al., 2013; Turri et al., 2016). Previous studies reported an inverse relationship between distance to traffic indicators and AMCL levels (Mason et al.; Bunn et al., 2001; Jacobs et al., 2010; Brugha et al., 2014; Momtaz et al., 2019). Momtaz et al. (2019) reported that there was a significant inverse relationship between distance to major roads and AMCL level (Momtaz et al., 2019). Moreover, a study by Jacobs et al. (2010) on 137 non-smoking adults with diabetes showed that the AMCL level was significantly higher in participants living near to major roads $(>100 \mathrm{~m})$ compared to those living away from major roads (Jacobs et al., 2010). Another study by Bunn et al. (2001) on 22 healthy children reported that the percentage of AMCL was significantly lower in children who lived on a quiet residential road compared with those living near major busy roads (Bunn et al., 2001). These results are in line with our findings. However, other studies on 49 children with asthma (Brugha et al., 2014) and on 14 COPD patients (Mason et al.) reported a non-significant relationship between distance to major roads and AMCL level, which are inconsistent with our findings.

\subsection{Study limitations}

We estimated the outdoor PM based on LUR models and we did not have any measurement of indoor PMs levels, while the pregnant women spent much of their time at home-indoor. We estimated PMs exposure based on the annual mean, which might not have perfectly matched with the pregnancy period of the participant. However, given that all pregnant women were recruited at their time of delivery and that our recruitment only lasted three months, the pregnancy periods of the study participants covered similar months of the year. Hence, we expect that the exposure misclassification due to our use of annual levels could be comparable among the participants. Moreover, we did not have data on personal monitoring of PM2.5 or black carbon for our participants. Similarly, we did not have access to data on traffic count and also the types of vehicles, which could be relevant determinants of the AMCL. The composition of PMs (e.g. elemental and organic carbon) was not measured, which might have been related to AMCL levels. Furthermore, we relied on self-reported weight and height of mothers before pregnancy that could have resulted in measurement errors. We also selected the healthy pregnant women with no pregnancy complications and they were housewives (i.e. they did not have occupational exposure), nonactive smokers, did not have any exposure to biomass smoke and did not have any background diseases. These inclusion and exclusion criteria were applied to increase the internal validity of our study; however, they could have limited the external validity of our findings. In our study setting about $83 \%$ of married women are housewives (based on last census in 2016) and only $8.7 \%$ of Iranian women are active smokers (Halimi et al., 2013). Finally, since AMCL gives an integrated 6-month exposure window, it might be difficult to infer the critical exposure period for specific pregnancy outcomes.

\section{Conclusions}

In this study, among 34 personal, indoor and home-outdoor determinates, we found that estimated $\mathrm{PM}_{2.5}$ concentration at the residential address was positively associated with AMCL level in pregnant women in a middle-income country. Moreover, distance to heavy-traffic lights, squares and ring-roads and having and duration of natural ventilation were inversely associated with AMCL. Furthermore, we observed some suggestions for a potential direct association of the duration of second-hand tobacco smoke at home and open-plan kitchen type and an indirect association of age with AMCL. If confirmed by other studies, these findings inform future studies of the health effects of the maternal exposure to air pollution during pregnancy about the 
important determinants of such an exposure to be considered in their studies. Moreover, they can provide the necessary evidence base for policy- and decision-makers to fine-tune and implement interventions to reduce maternal exposure to air pollution during pregnancy, particularly in LMICs. We recommended further research in other population settings with different potential determinates including home-indoor measures of air pollution to shed further light on the relationship between these determinants and AMCL levels in pregnant women.

\section{Author statements}

$\mathrm{MM}$, conceptualizing and designing the study, collecting the data and drafting the manuscript. HR, SMM, MLN, AA, NP, MA, MSB and ZR, collecting the samples and conducting the laboratory analyses. LA, carrying out the statistical analyses and contributing to model development. CT, XB, MN, JS and TN, conceptualizing the study and revising the manuscript. PD, conceptualizing and designing the study and revising the manuscript. All authors reviewed the manuscript, provided feedback, and concurred with its submission.

\section{Declaration of competing interest}

The authors declare that they have no known competing financial interests or personal relationships that could have appeared to influence the work reported in this paper.

\section{Acknowledgments}

We thank of the Shahidan Mobayani Hospital for their cooperation in this study. This study was supported by Sabzevar University of Medical Sciences [Grant number: 95075]. We acknowledge support from the Spanish Ministry of Science and Innovation through the "Centro de Excelencia Severo Ochoa 2019-2023" Program (CEX 2018-000806-S), and support from the Generalitat de Catalunya through the CERCA Program to ISGlobal.

\section{References}

Agier, L., Portengen, L., Chadeau-Hyam, M., Basagaña, X., Giorgis-Allemand, L., Siroux, V., Robinson, O., Vlaanderen, J., González, J.R., Nieuwenhuijsen, M.J., Vineis, P., Vrijheid, M., Slama, R., Vermeulen, R., 2016. A systematic comparison of linear regression-based statistical methods to assess exposome-health associations. Environ. Health Perspect. 124, 1848-1856.

Al Hanai, A.H., Antkiewicz, D.S., Hemming, J.D.C., Shafer, M.M., Lai, A.M., Arhami, M., Hosseini, V., Schauer, J.J., 2019. Seasonal variations in the oxidative stress and inflammatory potential of PM2.5 in Tehran using an alveolar macrophage model; the role of chemical composition and sources. Environ. Int. 123, 417-427.

Arfaeinia, H., Hashemi, S.E., Alamolhoda, A.A., Kermani, M., 2016. Evaluation of organic carbon, elemental carbon, and water soluble organic carbon concentration in PM2.5 in the ambient air of Sina Hospital district, Tehran, Iran. Journal of Advances in Environmental Health Research 4, 95-101.

Arhami, M., Shahne, M.Z., Hosseini, V., Roufigar Haghighat, N., Lai, A.M., Schauer, J.J., 2018. Seasonal trends in the composition and sources of PM2.5 and carbonaceous aerosol in Tehran, Iran. Environ. Pollut. 239, 69-81.

Bai, W., Li, Y., Niu, Y., Ding, Y., Yu, X., Zhu, B., Duan, R., Duan, H., Kou, C., Li, Y., Sun, Z., 2020. Association between ambient air pollution and pregnancy complications: a systematic review and meta-analysis of cohort studies. Environ. Res. 185, 109471.

Bai, Y., Bové, H., Nawrot, T.S., Nemery, B., 2018a. Carbon load in airway macrophages as a biomarker of exposure to particulate air pollution; A longitudinal study of an international Panel. Part. Fibre Toxicol. 15.

Bai, Y., Brugha, R.E., Jacobs, L., Grigg, J., Nawrot, T.S., Nemery, B., 2015a. Carbon loading in airway macrophages as a biomarker for individual exposure to particulate matter air pollution - a critical review. Environ. Int. 74, 32-41.

Bai, Y., Casas, L., Scheers, H., Janssen, B.G., Nemery, B., Nawrot, T.S., 2018b. Mitochondrial DNA content in blood and carbon load in airway macrophages. A panel study in elderly subjects. Environ. Int. 119, 47-53.

Bai, Y., Seys, S., Nawrot, T., Nemery, B., 2015b. Carbon loading in airway macrophages to traffic-derived particulate matter air pollution. Arch. Publ. Health 73, 1.

Barrera-Gómez, J., Agier, L., Portengen, L., Chadeau-Hyam, M., Giorgis-Allemand, L., Siroux, V., Robinson, O., Vlaanderen, J., González, J.R., Nieuwenhuijsen, M., Vineis, P., Vrijheid, M., Vermeulen, R., Slama, R., Basagaña, X., 2017. A systematic comparison of statistical methods to detect interactions in exposome-health associations. Environ. Health 16, 74.
Belli, A.J., Bose, S., Aggarwal, N., DaSilva, C., Thapa, S., Grammer, L., Paulin, L.M., Hansel, N.N., 2016. Indoor particulate matter exposure is associated with increased black carbon content in airway macrophages of former smokers with COPD. Environ. Res. 150, 398-402.

Bennett, W.D., Zeman, K.L., 2004. Effect of body size on breathing pattern and fineparticle deposition in children. J. Appl. Physiol. 97, 821-826.

Bennett, W.D., Zeman, K.L., Kim, C., 1996. Variability of fine particle deposition in healthy adults: effect of age and gender. Am. J. Respir. Crit. Care Med. 153, 1641-1647.

Brugha, R., Dickson, I., Grigg, J., 2012. Airway macrophage carbon content: interobserver reliability and surrogate markers for analysis. Am. J. Respir. Crit. Care Med. 185, A3232 ([Abstract]).

Brugha, R.E., Mushtaq, N., Round, T., Gadhvi, D.H., Dundas, I., Gaillard, E., Koh, L., Fleming, L.J., Lewis, D.J., Sanak, M., Wood, H.E., Barratt, B., Mudway, I.S., Kelly, F. J., Griffiths, C.J., Grigg, J., 2014. Carbon in airway macrophages from children with asthma. Thorax 69, 654-659.

Bunn, H.J., Dinsdale, D., Smith, T., Grigg, J., 2001. Ultrafine particles in alveolar macrophages from normal children. Thorax 56, 932-934.

Chang, T., Ren, D., Shen, Z., Huang, Y., Sun, J., Cao, J., Zhou, J., Liu, H., Xu, H., Zheng, C., Pan, H., He, C., 2017. Indoor air pollution levels in decorated residences and public places over xi'an, China. Aerosol Air Qual. Res. 17, 2197-2205.

Curto, A., Donaire-Gonzalez, D., Manaca, M.N., González, R., Sacoor, C., Rivas, I., Gascon, M., Wellenius, G.A., Querol, X., Sunyer, J., Macete, E., Menéndez, C. Tonne, C., 2019. Predictors of personal exposure to black carbon among women in southern semi-rural Mozambique. Environ. Int. 131, 104962.

Fullerton, D.G., Jere, K., Jambo, K., Kulkarni, N.S., Zijlstra, E.E., Grigg, J., French, N., Molyneux, M.E., Gordon, S.B., 2009. Domestic smoke exposure is associated with alveolar macrophage particulate load. Trop. Med. Int. Health 14, 349-354.

Halimi, L., Haghdoost, A.A., Mohammad Alizadeh, S., 2013. Prevalence of cigarette smoking among Iranian women: a systematic review and meta-analysis. Med. J. Islam. Repub. Iran 27, 132-140.

Hand, J.L., Schichtel, B.A., Malm, W.C., Frank, N.H., 2013. Spatial and temporal trends in $\mathrm{PM}_{2.5}$ organic and elemental carbon across the United States. Adv. Meteorol. 2013, 367674 .

ImageJ, 2020. https://imagej.nih.gov/ij/.

Jacobs, L., Emmerechts, J., Mathieu, C., Hoylaerts, M.F., Fierens, F., Hoet, P.H., Nemery, B., Nawrot, T.S., 2010. Air pollution-related prothrombotic changes in persons with diabetes. Environ. Health Perspect. 118, 191-196.

Kim, K.-H., Kabir, E., Kabir, S., 2015. A review on the human health impact of airborne particulate matter. Environ. Int. 74, 136-143.

Kulkarni, N., Pierse, N., Rushton, L., Grigg, J., 2006. Carbon in airway macrophages and lung function in children. N. Engl. J. Med. 355, 21-30.

Kulkarni, N.S., Prudon, B., Panditi, S.L., Abebe, Y., Grigg, J., 2005. Carbon loading of alveolar macrophages in adults and children exposed to biomass smoke particles. Sci. Total Environ. 345, 23-30.

Li, Z., Liu, Q., Xu, Z., Guo, X., Wu, S., 2020. Association between short-term exposure to ambient particulate air pollution and biomarkers of oxidative stress: a meta-analysis. Environ. Res. 191.

Linehan, E., Fitzgerald, D., 2015. Ageing and the immune system: focus on macrophages. European Journal of Microbiology and Immunology 5, 14-24.

Lundborg, M., Dahlén, S.E., Johard, U., Gerde, P., Jarstrand, C., Camner, P., Låstbom, L., 2006. Aggregates of ultrafine particles impair phagocytosis of microorganisms by human alveolar macrophages. Environ. Res. 100, 197-204.

Masjedi, M.R., Taghizadeh, F., Hamzehali, S., Ghaffari, S., Fazlzadeh, M., Jafari, A.J., Niazi, S., Mehrizi, E.A., Moradi, M., Pasalari, H., Arfaeinia, H., 2019. Air pollutants associated with smoking in indoor/outdoor of waterpipe cafés in Tehran, Iran: concentrations, affecting factors and health risk assessment. Sci. Rep. 9, 3110.

Mason, P., Kulkarni, N., Liviero, F., Guarnieri, G., Maestrelli, P., Determinants of carbon load in airway macrophages in COPD. B37. TELL ME WHY: COPD pathogenesis, pp. A2880-A2880.

McCreanor, J., Cullinan, P., Nieuwenhuijsen, M.J., Stewart-Evans, J., Malliarou, E., Jarup, L., Harrington, R., Svartengren, M., Han, I.-K., Ohman-Strickland, P., 2007. Respiratory effects of exposure to diesel traffic in persons with asthma. N. Engl. J. Med. 357, 2348-2358.

Melody, S.M., Ford, J., Wills, K., Venn, A., Johnston, F.H., 2019. Maternal exposure to short-to medium-term outdoor air pollution and obstetric and neonatal outcomes: a systematic review. Environ. Pollut. 244, 915-925.

Milà, C., Salmon, M., Sanchez, M., Ambrós, A., Bhogadi, S., Sreekanth, V., Nieuwenhuijsen, M., Kinra, S., Marshall, J.D., Tonne, C., 2018. When, where, and what? Characterizing personal PM2.5 exposure in periurban India by integrating GPS, wearable camera, and ambient and personal monitoring data. Environ. Sci. Technol. 52, 13481-13490.

Miri, M., Ghassoun, Y., Dovlatabadi, A., Ebrahimnejad, A., Löwner, M.-O., 2019. Estimate annual and seasonal PM1, PM2.5 and PM10 concentrations using land use regression model. Ecotoxicol. Environ. Saf. 174, 137-145.

Momtaz, S.M., Mehdipour, P., Dadvand, P., Ehrampoush, M.H., Ghaneian, M.T., Lotfi, M. H., Aliabad, A.S., Molavi, F., Zare Sakhvidi, M.J., 2019. Environmental and behavioral determinants affecting the association of airway macrophages carbon load with distance to major roads and traffic density. Chemosphere 217, 680-685.

Office, K.R.M., 2020. Province Climate Portal of Khorasan Razavi Meteorological Department [Internet]. Available from: https://www.razavimet.ir/fa/node/38.

Øvrevik, J., 2019. Oxidative potential versus biological effects: a review on the relevance of cell-free/abiotic assays as predictors of toxicity from airborne particulate matter. Int. J. Mol. Sci. 20.

Pavord, I., Pizzichini, M., Pizzichini, E., Hargreave, F., 1997. The use of induced sputum to investigate airway inflammation. Thorax 52, 498. 
Pongpiachan, S., Kositanont, C., Palakun, J., Liu, S., Ho, K.F., Cao, J., 2015. Effects of day-of-week trends and vehicle types on PM2.5-bounded carbonaceous compositions. Sci. Total Environ. 532, 484-494.

Rahman, S.M.A., Masjuki, H.H., Kalam, M.A., Abedin, M.J., Sanjid, A., Sajjad, H., 2013 Impact of idling on fuel consumption and exhaust emissions and available idlereduction technologies for diesel vehicles - a review. Energy Convers. Manag. 74, 171-182.

Rezaei Hachesu, V., Naderyan Fe'li, S., Kargar Shouroki, F., Mehrparvar, A.H., Zavar Reza, J., Azimi, M., Zare Sakhvidi, M.J., 2019. Carbon load in airway macrophages, DNA damage and lung function in taxi drivers exposed to traffic-related air pollution. Environ. Sci. Pollut. Control Ser. 26, 6868-6876.

Sanchez, M., Milà, C., Sreekanth, V., Balakrishnan, K., Sambandam, S., Nieuwenhuijsen, M., Kinra, S., Marshall, J.D., Tonne, C., 2020. Personal exposure to particulate matter in peri-urban India: predictors and association with ambient concentration at residence. J. Expo. Sci. Environ. Epidemiol. 30, 596-605.

Scheicher, M.E., Terra Filho, J., Vianna, E.O., 2003. Sputum induction: review of literature and proposal for a protocol. Sao Paulo medical journal $=$ Revista paulista de medicina 121, 213-219.

Schembari, A., Triguero-Mas, M., de Nazelle, A., Dadvand, P., Vrijheid, M., Cirach, M., Martinez, D., Figueras, F., Querol, X., Basagaña, X., Eeftens, M., Meliefste, K., Nieuwenhuijsen, M.J., 2013. Personal, indoor and outdoor air pollution levels among pregnant women. Atmos. Environ. 64, 287-295.

Shupler, M., Hystad, P., Birch, A., Miller-Lionberg, D., Jeronimo, M., Arku, R.E., Chu, Y. L., Mushtaha, M., Heenan, L., Rangarajan, S., Seron, P., Lanas, F., Cazor, F., LopezJaramillo, P., Camacho, P.A., Perez, M., Yeates, K., West, N., Ncube, T., Ncube, B., Chifamba, J., Yusuf, R., Khan, A., Hu, B., Liu, X., Wei, L., Tse, L.A., Mohan, D., Kumar, P., Gupta, R., Mohan, I., Jayachitra, K.G., Mony, P.K., Rammohan, K., Nair, S., Lakshmi, P.V.M., Sagar, V., Khawaja, R., Iqbal, R., Kazmi, K., Yusuf, S., Brauer, M., 2020. Household and personal air pollution exposure measurements from 120 communities in eight countries: results from the PURE-AIR study. The Lancet Planetary Health 4, e451-e462.

Soleimani, M., Amini, N., Sadeghian, B., Wang, D., Fang, L., 2018. Heavy metals and their source identification in particulate matter (PM2.5) in Isfahan City, Iran. J. Environ. Sci. 72, 166-175.
Spiru, P., Simona, P.L., 2017. A review on interactions between energy performance of the buildings, outdoor air pollution and the indoor air quality. Energy Proc. 128, $179-186$.

Tarnoki, A.D., Tarnoki, D.L., Travers, M.J., Hyland, A., Dobson, K., Mechtler, L., Horvath, I., Michael Cummings, K., 2011. Tobacco smoke is a major source of indoor air pollution in Hungary's hospitality venues. Eur. Respir. J. 38, p1082.

Timmers, V.R.J.H., Achten, P.A.J., 2016. Non-exhaust PM emissions from electric vehicles. Atmos. Environ. 134, 10-17.

Turri, V., Besselink, B., Johansson, K.H., 2016. Gear management for fuel-efficient heavy-duty vehicle platooning. In: 2016 IEEE 55th Conference on Decision and Control (CDC), pp. 1687-1694.

Valero, N., Aguilera, I., Llop, S., Esplugues, A., de Nazelle, A., Ballester, F., Sunyer, J. 2009. Concentrations and determinants of outdoor, indoor and personal nitrogen dioxide in pregnant women from two Spanish birth cohorts. Environ. Int. 35, 1196-1201.

Wei, T., Tang, M., 2018. Biological effects of airborne fine particulate matter (PM2.5) exposure on pulmonary immune system. Environ. Toxicol. Pharmacol. 60, 195-201.

White, C., Ryu, M.H., Kaufman, J.D., Kavanagh, T., Carlsten, C., Association between diesel exhaust inhalation and black carbon loading in airway macrophages in individuals with COPD. D26. HEALTH EFFECTS ASSOCIATED WITH INDOOR AND OUTDOOR AIR POLLUTION, pp. A6025-A6025.

Whitehouse, A.L., Miyashita, L., Liu, N.M., Lesosky, M., Flitz, G., Ndamala, C., Balmes, J. R., Gordon, S.B., Mortimer, K., Grigg, J., 2018. Use of cleaner-burning biomass stoves and airway macrophage black carbon in Malawian women. Sci. Total Environ. 635, 405-411.

WHO, 2021. Ambient (Outdoor) Air Pollution. Available at: https://www.who, int/news-room/fact-sheets/detail/ambient-(outdoor)-air-quality-and-health.

Wong, C.K., Smith, C.A., Sakamoto, K., Kaminski, N., Koff, J.L., Goldstein, D.R., 2017. Aging impairs alveolar macrophage phagocytosis and increases influenza-induced mortality in mice. J. Immunol. 199, 1060-1068.

Zhao, M., Xu, J., Li, A., Mei, Y., Ge, X., Liu, X., Wei, L., Xu, Q., 2020. Multiple exposure pathways and urinary chromium in residents exposed to chromium. Environ. Int. 141. 